\title{
A moralidade da nanotecnologia
}

\author{
The morality of nanotechnology
}

\begin{abstract}
${ }_{1}^{1}$ Programa de Pós-graduação em Bioética, Universidade de Brasília, Brasília, Brasil. 2 Escola Nacional de Saúde Pública Sergio Arouca, Fundação Oswaldo Cruz, Rio de Janeiro, Brasil.

Correspondência M. Pyrrho

Programa de Pós-graduação em Bioética, Universidade de Brasília.

Campus Universitário Darcy Ribeiro, Brasília, DF 70904-970, Brasil. pyrrho.monique@gmail.com
\end{abstract}

\section{Abstract}

Nanotechnology is a set of knowledge, techniques, and practices in studying and exploring new properties of materials that arise when manipulated at the atomic and molecular levels. The technical possibility of organizing and controlling matter at the smallest dimensions and units can result in profound changes in industrial production processes and have significant moral impacts on human relations, organization of the current social order, and even life as a phenomenon. However, moral reflection on nanotechnology has been criticized over the assertion that nanotechnology fails to raise any new ethical issue, for example. The current article discusses the limits of this claim by presenting two aspects that distinguish between nanotechnology and earlier biotechnoscientific advances in terms of their ethical implications: (a) uncertainty as an epistemic characteristic and (b) the threat to the current symbolic character of DNA as the "code of life".

Nanotechnology; Bioethics; Nanostructures; DNA
Monique Pyrrho 1

Fermin Roland Schramm 2

\section{Introdução}

A nanotecnociência surgiu no final do século XX como uma nova promessa de rápidos avanços e profundos impactos sobre a vida humana futura. De fato, a capacidade técnica de manipular a matéria na dimensão de seus átomos e moléculas está revelando novas propriedades de materiais já conhecidos, permitindo a produção de dispositivos e compostos novos, cujas aplicações - se concretizadas - incrementariam quase todo tipo de produção tecnológica atual: de fármacos a vestimentas, da indústria alimentar à indústria naval 1.

Resultado da interação dos conhecimentos de física quântica, biologia molecular, eletrônica, química e engenharia de materiais 2 , a nanotecnociência estuda e explora as propriedades dos materiais quando manipulados em nível atômico e molecular. Altera propriedades como cor, condutividade elétrica, resistência e dureza em relação às amostras macroscópicas ${ }^{3}$.

Essas novas propriedades são objeto de interesse de diversas áreas, como informática, aeronáutica, química, energia, indústria bélica $\mathrm{e}$ quase todos os ramos de indústrias de alta tecnologia atuais 4 . Seu uso parece ser ainda mais promissor para as áreas biomédicas, nas quais se anuncia a possibilidade de cirurgias menos invasivas e mais eficazes, medicamentos com maior especificidade, tratamentos de doenças 
como câncer e até a melhora de processos cognitivos e da memória ${ }^{3}$.

A pesquisa sobre aspectos técnicos e científicos da nanotecnologia recebe crescentes investimentos e alguns produtos já chegam ao consumidor, como medicamentos, cosméticos e vestimentas. Embora muito analisado e explorado pelas ciências exatas e naturais, este fenômeno recente $\mathrm{e}-\mathrm{o}$ que mais interessa aqui - suas possíveis consequências éticas são ainda em boa parte desconhecidas pela população em geral 5 .

Neste estudo, abordaremos a moralidade da nanotecnologia, entendida como o conjunto de argumentos morais utilizados para sua aceitação ou sua recusa.

\section{Nanotecnologia e seus riscos}

Historicamente, com a promessa de grandes avanços e investimentos que acompanham a nanotecnologia, surgiu uma série de áreas "nano", indicadas pelos termos nanobiotecnologia, nanofísica, nanoquímica, nano-óptica, nanoeletrônica, nanorrobótica e nanomedicina. Referem-se a áreas tradicionais de conhecimento, mas incorporam materiais e dispositivos manipulados nanometricamente às suas práticas, com o objetivo de se beneficiar das novas propriedades. Em particular, termos como nanoeconomia, nanodireito e nanoética indicam uma potencial transformação de conhecimentos, práticas, instituições e ferramentas normativas, após a incorporação da nanotecnologia em nosso cotidiano.

Entretanto, alguns conceitos, como nanopartículas, nanomateriais, materiais nanoestruturados e materiais nanoengenheirados, merecem atenção especial. As "nanopartículas" são partículas em que ao menos uma das dimensões é nanométrica, ou seja, ao menos uma das dimensões tem um tamanho entre $1 \mathrm{~nm}$ a $100 \mathrm{~nm}$, correspondendo a estruturas atômicas e moleculares. Estas nanopartículas não são necessariamente produtos da ação humana e se encontram naturalmente dispersas no meio ambiente, como partículas de poeira e cinzas, por exemplo. Já os chamados "nanomateriais", "materiais nanoestruturados" ou "materiais nanoengenheirados" são sempre sintetizados pelo homem 2 .

Materiais nanoestruturados podem consistir em blocos microscópicos ou macroscópicos de um material que, durante seu processo de fabricação, sofreu algum tipo de estruturação ou manipulação em nível nanométrico. Eles podem ser utilizados para construir uma diversidade de produtos e dispositivos mais ou menos complexos, conhecidos por sua vez como nanoprodutos e nanodispositivos, respectivamente 2 .
Hoje, já há grande diversidade de nanomateriais, dentre eles: derivados do carbono, derivados metálicos e polímeros; suas aplicações são muito amplas, desde a síntese de componentes eletrônicos, até agentes terapêuticos e produtos para detoxificação do solo ${ }^{2}$. A incorporação crescente da nanotecnologia por quase todos os ramos tecnológicos industriais faz com que consumidores e trabalhadores estejam cada vez mais em contato com materiais nanoestruturados. A exposição aos nanomateriais e nanopartículas pode ocorrer em diferentes contextos: por contato com roupas e produtos químicos, pela ingestão de medicamentos e pela inalação derivada da exposição massiva e continuada de trabalhadores das indústrias e moradores das zonas industriais. Devido ao estágio inicial da produção nanotecnológica, os estudos produzidos até o momento são uma combinação de métodos de aferição de espaços reais de trabalho e simulações em laboratório 6 .

Com o objetivo de analisar a potencialidade tóxica das nanopartículas, surgiu o campo da nanotoxicologia. As pesquisas nesta área, ainda em seus primórdios, têm sugerido que a diminuição da dimensão torna os compostos quimicamente mais reativos, o que acelera a disseminação das partículas em solução. Adicionalmente, o tamanho das partículas facilita sua passagem pelas membranas celulares e outras membranas intracelulares, como a nuclear. Já no conteúdo citoplasmático, as partículas podem interagir e, até mesmo, hibridizar com estruturas subcelulares, como microtúbulos e DNA. Ademais, há indícios de uma intensificação das respostas fisiológicas e patológicas à presença das nanopartículas, quando estas são comparadas a partículas que não sofreram o mesmo processo de síntese e estruturação. Por exemplo, foram relatados efeitos como aumento da resposta inflamatória, fibrose, respostas alérgicas, genotoxicidade, carcinogenicidade e, em estudos preliminares em animais, foram afetadas as funções cardiovascular e linfática 7.

A toxicidade das nanopartículas e dos materiais nanoestruturados depende de uma interação complexa de fatores como tamanho, concentração, tempo de exposição, estado de saúde e características individuais do organismo exposto 2 . No entanto, seria um erro afirmar que os mecanismos de toxicidade das nanopartículas são plenamente conhecidos 8 . Isso se dá porque aquilo que faz a nanotecnologia parecer tão promissora - o comportamento diverso das nanopartículas em relação às formas brutas do mesmo material - é também aquilo que torna seus potenciais efeitos sobre a saúde e sobre o meio-ambiente imprevisíveis 9. 
Ao desconhecimento parcial das propriedades dos materiais, conjuga-se o fato de que os atuais mecanismos de regulação baseiam-se somente na composição química dos materiais, não levando em conta o processo de síntese e a conformação química dos compostos. Apesar de os estudos científicos apontarem repetidamente para o surgimento de propriedades e perfis de toxicidade diversos e relacionados à manipulação nanoescalar dos materiais, as agências e mecanismos de controle e regulação têm negligenciado este aspecto, mantendo os mesmos sistemas de classificação e testes usados em outros materiais, considerando novos materiais nanoestruturados como bioequivalentes a seus materiais brutos correspondentes. Essa postura dos mecanismos reguladores possibilita, por exemplo, que um novo composto nanoestruturado chegue ao mercado de medicamentos sem passar por novos testes de toxicidade, desconsiderando que as reações orgânicas podem ser completamente diversas 10 .

Os impactos, positivos ou negativos, das aplicações nanotecnológicas não se limitam aos seres humanos, pois a questão ambiental é um tópico bastante enfatizado quando a pauta é nanotecnologia. A produção de tecnologias e produtos com impacto ambiental diminuído, como dispositivos para captação de energia fotovoltaica, é uma das principais vertentes à qual se dedica a nanotecnologia. Em particular, destacam-se os nanomateriais orgânicos ou derivados do carbono, que têm sido empregados no desenvolvimento de dispositivos para absorção, filtração e controle de patógenos; na fabricação de sensores ambientais e de mecanismos para captação e armazenamento de energia renovável; e na prevenção da poluição ambiental 11 .

Contudo, nem todos os tipos - tampouco todos os usos - dos materiais nanoestruturados trazem resultados ambientais positivos; sua produção, seu uso e sua consequente liberação no meio ambiente precederam a necessária avaliação do impacto sobre os ecossistemas. Atualmente, não há dados sobre as concentrações desses materiais no meio ambiente, sobre sua distribuição ou sobre suas formas físico-químicas quando em contato com os diferentes ecossistemas. É necessário, ainda, desenvolver técnicas de identificação e mensuração desses materiais em meios atmosféricos, aquáticos e terrestres, já que as abordagens clássicas não consideram as novas características de comportamento, destinação, biodisponibilidade e toxicidade dos novos materiais 12 .

\section{Não só de riscos vive a ética}

Os rápidos avanços da nanotecnologia e seus potenciais impactos sobre a saúde e o meio-ambiente são os aspectos eticamente significativos mais frequentemente abordados pela produção científica sobre o tema. Porém, as discussões sobre as consequências éticas das aplicações nanotecnológicas - e que constituem a problemática da moralidade da nanotecnologia - não se reduzem aos campos da saúde e da ecologia. $\mathrm{Na}$ atualidade, existem ainda questões relacionadas à equidade na distribuição dos benefícios e acesso aos avanços tecnocientíficos; implicações quanto à privacidade e segurança (equipamentos de monitoramento invisíveis e infinitas possibilidades para a indústria bélica); consequências sociais, culturais e econômicas da modificação da constituição de seres vivos etc. 13 .

Resultado da vigência do paradigma biotecnocientífico 14, a nanociência representa uma tentativa de se apropriar de um território até agora inexplorado do mundo, a nanoescala 15 . Assim, a possibilidade de rearranjar átomo a átomo parece ser o que faltava para conhecer e manipular o universo, desde sua menor parte; aquilo que nos propiciaria, por fim, interferir na evolução humana, proporcionando corpos e mentes "perfeitos". Por vezes denominada Síndrome do Santo Graal 16 , esta fascinação em torno dos desenvolvimentos tecnocientíficos atinge níveis extremos e faz parecer sempre que esse avanço seria aquilo que faltava para compreender o universo e, também, para alcançar a vida eterna, quer seja por um corpo perfeito, melhorado; quer seja pela mente, supostamente cada vez mais potente e compatível com as máquinas disponíveis.

O intento de controlar processos orgânicos e seres vivos, para adaptar a "natureza" humana aos seus próprios desejos e projetos, parece ser, hoje, o objetivo prático da vigência do paradigma biotecnocientífico no campo formado pelas ciências da vida e as ciências da saúde, aparentemente justificado do ponto de vista sanitário e, também, eticamente. Logo, o paradigma biotecnocientífico pode ser conceituado, em perspectiva utilitarista, como um conjunto de ferramentas teóricas e práticas que visam a possibilitar a diminuição do sofrimento e a melhora das condições de vida, buscando superar as limitações impostas pela condição orgânica da vida humana por meio da reprogramação da nossa "natureza", interferindo, assim, na evolução biológica para melhorar a qualidade de vida 17 .

O aspecto eticamente significativo, aqui, é que a biotecnociência não consiste apenas na busca por conhecer os processos biológicos - como um objeto de saber teórico. É, fundamentalmente, 
um saber-fazer guiado para a intervenção sobre seres e processos vivos, entendidos não somente em sua dimensão orgânica, mas também - no caso dos humanos - nas dimensões simbólica, imaginária e técnica, o que desperta os sentimentos opostos e extremos de fascínio e medo em relação a esta nova forma de competência humana 17.

À Bioética, neste cenário, cabe investigar as possíveis implicações morais envolvidas pelos avanços biotecnocientíficos, ao mesmo tempo em que busca promover um olhar analítico, sóbrio e crítico sobre riscos e percepções sociais das novas tecnologias. Surge, portanto, como uma ferramenta alternativa para encarar os desafios impostos pela biotecnociência, provendo, em princípio, leitura racional e imparcial sobre as possíveis implicações morais das transformações causadas pelas biotecnologias à condição humana, que deverão ser resolvidas praticamente. Em suma, a Bioética serve tanto como caixa de ferramentas analíticas, quanto como contraponto normativo no diálogo com o paradigma biotecnocientífico, pois pretende analisar de forma crítica os argumentos a favor de e contra a utilização dos artefatos biotecnológicos 17. Evita, dessa forma, não só uma perspectiva tecnofílica, que superestima o caráter positivo das biotecnologias e subdimensiona seus riscos, mas também uma visão tecnofóbica, a qual, por temer transformações apocalípticas do mundo e do ser humano como o conhecemos, propõe, por exemplo, a interdição de qualquer tecnologia que ameace os interesses das próximas gerações.

A nanotecnologia também vivencia essa dualidade de percepções. Enquanto cientistas e grande parte da mídia enfatizam os fantásticos potenciais da nanotecnologia, principalmente para a área biomédica, ecologistas e ambientalistas questionam seus impactos ambientais inesperados. As narrativas sobre a nanotecnologia variam entre os extremos do pavor e do entusiasmo. Por exemplo, os discursos tecnofóbicos consideram que o poder técnico supera a capacidade de julgamento moral e que, em face dos riscos envolvidos, melhor seria a proibição sem mais, das práticas nanotecnocientíficas 18 . Em contraposição, o argumento tecnofílico defende que o objetivo do desenvolvimento científico é melhorar a vida humana, enaltecendo a potencialidade que a nanotecnologia tem para transformar a ciência, o ambiente e o próprio homem. Em outros termos, nesta segunda visão, a tecnologia é entendida como um conjunto de dispositivos e mecanismos inócuos a priori, cujos possíveis desdobramentos morais derivariam tão somente das formas e dos objetivos de seus usos, em princípio calculáveis e contro- láveis. Todavia, este "minimalismo" ético não considera que o trabalho da ciência ultrapassa o conjunto de conhecimentos científicos comprovados e justificados; que a ciência é um dispositivo dinâmico, composto por práticas, ações e instituições, destinadas a certas finalidades, em função de um panorama de desejos, interesses e valores envolvidos. Da mesma forma, um sistema técnico inclui também as pessoas e os fins que perseguem, assim como os conhecimentos, as crenças e valores que comportam ao operar as tecnologias 19 .

Nesta discussão, entre o pessimismo da razão da tecnofobia e o otimismo da vontade da tecnofilia 20 , o que parece estar em cheque (ou pelo menos em questão) é a própria condição humana. Isto porque a narrativa sobre a biotecnociência, enquanto, em parte, torna o homem capaz de interferir sobre sua própria vida e identidade, de modo a transformá-la em algo novo, ainda não conhecido, põe a questão: que vida é esta a ser transformada?

A questão é pertinente porque, de fato, as implicações éticas sobre a nanotecnologia não se encerram nas questões de biocompatibilidade e ecologia, pois, para enfrentar o debate sobre ética e nanotecnologia em sua plenitude, é ainda necessário encarar os cientistas como produtores culturais criativos e dar conta das formas pelas quais os instrumentos e as infraestruturas materiais da ciência conformam a compreensão socialmente compartilhada de sua prática. Em suma, é preciso esclarecer o que a ciência tem por objetivo revelar e aquilo que escolherá obscurecer, reprimir e retirar do cenário 21.

Mas um empreendimento de tal dimensão demanda exercício minucioso de fazer emergir as concepções, ideias e imagens que conformam a teoria científica, assim como analisar a determinação recíproca entre ciência e sociedade para, somente então, proceder a uma análise crítica e a um julgamento normativo dos avanços tecnológicos.

\section{Dois aspectos éticos da nanotecnologia}

A reflexão ética sobre a nanotecnologia, desde seus primeiros momentos, tem enfrentado muitas críticas, inclusive sobre sua pertinência em avaliar este saber-fazer científico. O principal argumento é que a nanotecnologia não apresentaria nada de novo do ponto de vista ético; por isso, o que se apresenta como realmente necessário é um maior investimento em métodos de investigação científica, como toxicologia e estudos de impacto, supostamente capazes de prever e prevenir os principais riscos envolvidos 22 . 
De fato, o motivo pelo qual a nanotecnologia desperta tanta atenção - a promessa de potencializar as capacidades humanas - é, de certa forma, uma constante que acompanha todas as tecnologias. É também verdade que as questões que levanta - como as relacionadas à privacidade e à condição humana - não representam problemas éticos novos 23 . Adicionalmente, até $o$ momento, tanto a capacidade técnica quanto as consequências de reconfigurar tão precisamente o humano, molécula a molécula, a partir de seus códigos, são somente "possibilidades", razão pela qual as discussões éticas têm sido criticadas por seu mero caráter especulativo 24.

Entretanto, se a nanotecnologia falha em apontar novas questões éticas, isso não significa necessariamente que a reflexão ética sobre elas seja dispensável. Com efeito, ainda que as questões éticas sejam as mesmas referentes aos anteriores avanços tecnocientíficos, essas questões seguem necessitando de respostas 25 .

Este artigo mostra os limites dessa afirmação e, para tanto, apresenta dois aspectos que diferenciam a nanotecnologia dos anteriores avanços biotecnocientíficos em suas possíveis implicações éticas, abordadas, por exemplo, pela nanoética: (a) a incerteza como característica epistêmica e (b) a ameaça ao presente caráter simbólico de código da vida do qual está imbuído o DNA.

\section{A incerteza}

Provavelmente, a nanotecnologia não será o derradeiro avanço tecnológico, assim como os anteriores não o foram. Contudo, embora não seja possível afirmar que os desafios éticos que impõe sejam completamente novos 25,26, há algo que ao menos se potencializa na nanotecnologia: não os riscos em si, mas a impossibilidade de calculá-los.

Mais especificamente, o que faz a biotecnociência trazer consequências éticas importantes não é somente a transformação de formas de vida já conhecidas, mas a criação de novas formas de vida. Isso traz - juntamente com os benefícios esperados - uma expansão ilimitada dos riscos. De forma semelhante, a nanotecnologia propicia a criação de materiais novos, o que também aumenta os riscos de forma incontrolável. Em adição - e isto é novo -, a nanotecnologia é fundada, ela mesma, sobre esta imprevisibilidade de resultados 27 .

Assim sendo, o primeiro aspecto eticamente significativo que aqui se destaca sobre a nanotecnologia refere-se ao que ela apresenta de inovador em relação às demais biotecnologias. Por se basear em propriedades imprevistas e desconhecidas, resultantes da manipulação em níveis nanoescalares, a nanotecnologia não somente pode criar materiais novos cujos riscos são desconhecidos, mas, ao alterar a disposição molecular e atômica de compostos já conhecidos, também pode trazer efeitos imprevisíveis com suas novas propriedades. De fato, além de os materiais novos poderem trazer riscos, a alteração daqueles já conhecidos pode ter consequências imprevisíveis. O que realmente importa é que essas consequências podem, igualmente, não ser mensuráveis pelo conhecimento científico atual 28.

Entretanto, não somente os riscos não podem ser calculados com precisão (na verdade, já não o eram com as demais biotecnologias em seus estágios iniciais); os efeitos, em si, não são previsíveis. É justamente isto o que a nanotecnologia parece ter de especial, ou ao menos mais destacado em relação às outras biotecnologias: representar uma situação epistêmica nova, em que incerteza e ignorância são intrínsecas, fundantes para este novo campo de conhecimento 27 . Assim, torna-se pouco realística a expectativa de prever as possibilidades de uso dos materiais e dispositivos, sendo ainda menos tangível aquela de saber as consequências reais de seu uso.

Neste caso, a principal sugestão seria a adoção do princípio da precaução, já que as implicações do uso de nanomateriais têm a ver com a falta de certeza científica. Baseadas neste princípio, a análise de riscos e a regulação visariam a eliminar os riscos humanos e ambientais ou, ao menos, reduzi-los a níveis aceitáveis, como acontece com os compostos químicos convencionais. Mas, no caso das nanopartículas, se as possíveis maneiras de exposição e os prejuízos a ela associados são desconhecidos, então o risco só poderá ser delimitado se a liberação for evitada 29.

O princípio da precaução é, via de regra, concebido para ser usado se uma ação expõe a um determinado risco ou perigo. Embora os dois estados não possam, em princípio, ser confundidos, já que o risco tem a ver com probabilidades e potencialidades, ao passo que o perigo se refere, em tese, a algum grau de certeza, na argumentação existe, muitas vezes, uma transição semântica sub-reptícia do primeiro conceito para o segundo, pois se inicia com um estado potencial - o risco - e infere-se um estado atual - o perigo -, referido a causas de danos reais. Em outros termos, na aplicação do princípio da precaução, admite-se que a ação prescrita possa variar de acordo com a percepção da gravidade da ameaça - que se situa entre "riscos" e "danos" - e que a percepção do evento ameaçador seja plausível segundo o conhecimento científico existente, ainda que sua probabilidade de causar danos 
não possa ser calculada com precisão ${ }^{17}$. Em particular, no caso dos produtos nanoestruturados, o uso do princípio recomendaria a realização de análises de risco aprofundadas e, talvez, a desaceleração da produção até que a natureza do perigo seja conhecida (admitindo que esta seja uma possibilidade). Quanto à questão da privacidade, especificamente, a precaução consistiria na regulação do uso antes da ampla disponibilização das tecnologias ditas invasoras 30 .

No entanto, a utilização do princípio da precaução como parâmetro ético para tomadas de decisão pertinentes às aplicações nanotecnológicas tem recebido muitas críticas. Logo, há indícios de que o princípio parece não surtir efeitos consistentes, ao menos não os esperados. Os riscos acabam por ganhar dimensão ainda mais significativa no debate sobre a nanotecnologia, não necessariamente porque sejam maiores, mas justamente porque os mecanismos atuais de regulação e controle tornam-se insuficientes e até mesmo inadequados, em face da incerteza e imprevisibilidade características do campo 31. Ademais, as críticas a respeito da análise de riscos assentam-se numa inevitável imprecisão - que tal abordagem traria -, já que o conhecimento não é conhecimento pleno agora e pode não o ser jamais. Nesta situação, a ferramenta a que se recorre com frequência para remediar a dificuldade de se predizer os rumos do desenvolvimento científico, representada pelo princípio da precaução, deve partir do pressuposto de que os efeitos negativos sejam conhecidos, mas acaba concluindo que a quantificação dos riscos é impossível por falta de dados 28 .

Assim sendo, o princípio da precaução não parece oferecer utilidade, ou acaba por reduzirse a um discurso que não surte efeito, gerando regras incoerentes e paradoxais para a tomada racional de decisões, resultando em inércia 32,33,34. Consequentemente, a precaução diante de riscos não mensuráveis parece um recurso precário para enfrentar a vida prática, e sua interação com as disposições do mercado torna necessária uma construção mais ampla dos parâmetros de análise.

Cabe à Bioética o exercício de abordar eticamente um conhecimento científico que não só apresenta evolução imprevisível (como qualquer outro), como também se baseia na imprevisibilidade. Portanto, pode-se dizer que a nanotecnologia impele a bioética e a biossegurança a encontrar novas ferramentas, já que as análises de risco e o princípio da precaução ficam praticamente esvaziados (ainda que não necessariamente inutilizáveis) 17.

De fato, o debate ético e bioético sobre a nanotecnologia dedicam-se expressivamente a tópicos como a análise de riscos, a precaução, a necessidade de regulação e governança, o engajamento público e a reflexão epistêmica a respeito dos limites do conhecimento. Porém, nem os tópicos nem os enfoques oferecidos até o momento alcançam a complexidade dos fenômenos sociais envolvidos, da dinâmica conflituosa dos interesses e dos discursos envolvidos na relação entre nanotecnologia e sociedade. Em síntese, do presente debate, emerge cada vez mais a necessidade de atentar para os papéis sociais desempenhados por ciência e tecnologia. Assim, têm se intensificado os esforços de contextualização da interface nanotecnologia/ sociedade, com o intuito de prover parâmetros para a análise da moralidade da nanotecnologia, buscando-se a compreensão de aspectos sociais, econômicos, históricos e filosóficos que determinam e, ao mesmo tempo, são determinados pela interação entre desenvolvimento tecnocientífico e sociedade 28 .

Ademais, a nanotecnologia surge em um cenário em que iniquidades sociais e danos ao meio-ambiente não somente existem, mas, por vezes, são alimentados por estabelecidas instituições e práticas sociais que favorecem grandes indústrias em detrimento do bem-estar das populações. Por isso a importância da análise de conjunturas mais amplas, como a distribuição geopolítica dos possíveis benefícios e riscos da nanotecnologia. Há razões, por exemplo, para se acreditar que os possíveis riscos ambientais se concentrarão em áreas industriais, em torno das quais geralmente habita uma população mais desabastecida e menos apta socialmente para defender seus próprios interesses 35

A dimensão ética da nanotecnologia, portanto, é resultante da conjunção de mais de um determinante. Por exemplo, os resultados socioeconômicos, positivos ou negativos, dependem de quais materiais nanoestruturados serão produzidos e para que finalidade; como e onde serão manufaturados; quais fatores são preponderantes para essas determinações; quais são as instâncias decisórias e reguladoras e sua efetividade. Estes aspectos, todavia, não são motivados pela nanotecnologia ou pelo conhecimento científico que a promove, pois respondem a conjunturas políticas e sociais que determinam áreas prioritárias de investimento, aplicações e usos legitimados socialmente, entre outros 35 .

Dessa forma, o que de fato tem consequências éticas e sociais não são a dimensão e os processos nanoescalares propriamente, mas a nanotecnologia enquanto um rico conjunto de indícios dos fenômenos sociais e culturais relacionados ao desenvolvimento tecnocientífico 28. Ferramentas como a análise de narrativas 
ganham importância crescente no debate ético sobre a nanotecnologia. O objetivo deste tipo de abordagem é identificar as intenções e as concepções dos diferentes atores envolvidos no debate, as maneiras como essas narrativas atuam para determinar a opinião pública e o modo como tais conjunturas determinam o direcionamento da produção de derivados nanotecnológicos, sua aceitação social e seu consumo 36 .

Dependendo da narrativa, é possível perceber que alguns dos possíveis impactos éticos da nanotecnologia recebem mais importância que outros. Por exemplo, a maior parte das abordagens éticas destaca os possíveis impactos sobre a saúde humana e sobre o meio-ambiente, em detrimento de outras implicações éticas derivadas das interações complexas tramadas entre sociedade, tecnologia, ambiente, política e economia ${ }^{37}$.

\section{A condição humana}

Apesar de muitas divergências quanto à abordagem e aos possíveis efeitos éticos da nanotecnologia, uma das representações mais frequentes e disseminadas entre todas as concepções e imagens de nanotecnologia é o caráter fundamentalmente revolucionário do campo 38,39,40,41. Alguns autores a consideram até como a próxima revolução industrial 42,43. Esta acepção de "ruptura", compartilhada por cientistas, agentes políticos, empresários, autores de ficção científica e mesmo cientistas sociais e filósofos, não se dá sem motivos.

Entre os recentes avanços tecnocientíficos, um bom exemplo de ruptura, que foi bem além de seu âmbito científico, é a profunda transformação na concepção de sociedade e parentesco que o estudo da genética introduziu, em que a forma de narrar e perceber as relações familiares e de explicar características da personalidade foram decisivamente alteradas 44 . Em novelas, jornais, programas televisivos e nos mais diversos meios de comunicação, os genes parecem explicar todas as dimensões humanas, como, por exemplo, a obesidade, a criminalidade, a timidez, a inteligência, as preferências sexuais. São citados os genes do egoísmo, da violência, da celebridade, da homossexualidade, da depressão e até da genialidade. A genética é também fundante para a constituição familiar atualmente: é nela que está inscrita a necessidade biológica de formar uma família e transmitir sua carga genética; ou seja, as relações de parentesco são redefinidas e estruturam uma família em que os laços de tradição, história, experiências e recordações comuns são menos importantes do que partilhar a mesma carga genética 45 . Em adição, esses discursos refletem a importância do gene e do DNA como ícones culturais, sustentados e legitimados pela existência de programas científicos importantes dedicados a estudos sobre genética. São estes estudos que acabam por dar credibilidade às explicações genéticas de um número sempre crescente de aspectos e comportamentos humanos 45 .

É justamente a apropriação do objeto de estudo da genética pela chamada revolução nanotecnológica que será destacado aqui como o segundo, e talvez mais importante, aspecto, eticamente significativo, da nanotecnologia.

A nanotecnologia, reiterada e exaustivamente apresentada como revolucionária, parece colocar ao alcance das mãos a possibilidade técnica de alcançar todas as pretensões humanas de organizar e controlar o mundo, desde sua menor unidade. A nanobiotecnologia, particularmente, aliada a técnicas de engenharia moderna, promete interferir, modificar e modelar qualquer característica do humano, do seu corpo e da sua mente, de acordo com sua própria conveniência 46 .

É justamente pelas expectativas de impacto sobre o ser humano, seu corpo, sua identidade individual e social que a nanotecnologia é tomada como revolucionária, e é por levantar a questão da condição humana que o debate sobre a área adquire tamanha importância. Com efeito, se, à primeira vista, a condição humana - como objeto de intervenção e dimensão ética fundamental - parece ser comum às demais biotecnologias, a intervenção nanotecnológica não se dá da mesma forma que as propostas anteriores, pois, segundo o discurso científico, o controle absoluto proporcionado pela nanotecnologia sobre a síntese de produtos e dispositivos permitirá que outras tecnologias alcancem suas metas antes inatingíveis. Assim, dispositivos nanotecnológicos permitiriam, enfim, a manipulação genética eficaz, possibilitando a terapia gênica. Seriam, também, dispositivos nanoestruturados a tornar cada vez mais compatíveis a memória humana e os atuais computadores 41 .

Assim sendo, o discurso científico acaba por cultivar expectativas que extrapolam o conhecimento e as capacidades até agora acumulados: o corpo poderia ser manipulado de forma a alcançar novas habilidades, a aumentar força e resistência física, dando origem, por exemplo, a uma nova horda de superatletas e supersoldados. Por outro lado, no embalo da cibercultura, os nanodispositivos permitiriam uma digitalização de nossas memórias feitas por interfaces homem/ máquina. Esta possibilidade leva à expectativa de uma existência sem corpo, imortal e virtual. Diante disso, a nanotecnologia possibilitaria um melhoramento do humano, por meio de duas 
vertentes aparentemente paradoxais: agiria para tornar o corpo perfeito, ou para torná-lo obsoleto e desnecessário 47.

Portanto, se o principal discurso sobre as nanotecnologias afirma que - para o bem ou para o mal, pelo corpo ou pela mente - elas transformarão profundamente o que conhecemos por humano, e que é nisso que fundamentalmente se assenta seu caráter revolucionário, as implicações éticas são importantes. Além disso, dado o papel determinante do discurso científico nas formas de representar o homem e seu entorno, a narrativa científica sobre futuras transformações na condição humana tem o poder de mudar a maneira de representá-la.

Mas o aspecto do discurso científico, que parece mais significativo do ponto de vista ético, é o anúncio do DNA como material ideal para quase todo fim. Justificado por sua flexibilidade sua fácil sujeição à manipulação e pela possibilidade de se autorreplicar a partir da programação estrutural desejada, o uso do DNA teria tantas finalidades quantas a imaginação permitisse 48 .

Ao descrever suas pesquisas, os cientistas afirmam que a nanotecnologia nos convidaria a olhar a molécula de uma forma nova e ainda mais promissora. A possibilidade infinita de obter conformações diversas do DNA permitiria que a molécula servisse como material para os mais diversos fins, como a produção de chips, e como molde para produzir outros nanomateriais 49 .

Como já vimos, esse convite a despir o DNA de seu caráter simbólico não se dá sem motivos, pois, ao desejar manipulá-lo, replicá-lo e usá-lo massivamente como material e amparo para a produção de outros materiais, sua representação como "código da vida" seria contraprodutiva, já que despertaria medo no público em geral. Por essa razão, o uso do DNA como material nanotecnológico por excelência, em suas dimensões simbólica e discursiva, certamente impactarão sobre a opinião pública. Em particular, a eleição do DNA como material nanotecnológico ideal ilustra a presente concepção de condição humana no discurso científico ao mesmo tempo em que a ameaça.

Historicamente, a discussão antiga sobre o que caracteriza a condição humana recebeu novo fôlego após a separação cartesiana entre corpo e mente. Essa dicotomia tornou-se determinante para a caracterização do humano na sociedade ocidental contemporânea 50 e, atualmente, parece ser substituída pelo determinismo genético, aplicável tanto ao corpo como à mente. Logo, o paradigma biotecnocientífico e a revolução prático-cognitiva envolvida, instaurada pela descoberta da relação entre hereditariedade genética e a molécula de DNA, inauguraram um novo ca- pítulo sobre a condição humana e aquilo que a determina ${ }^{51}$. Isto porque a descoberta do DNA, e o mais recente Programa Genoma Humano, estabeleceram o chamado "essencialismo genético", denominação que expressa a função do DNA na sociedade ocidental. Na prática, o código genético se apresentou como uma alternativa científica, clara e objetiva, para a explicação da origem e manutenção da vida 45 .

A questão da condição humana, tão cara à bioética e presente em tantas (se não em todas) as temáticas por ela abordadas, é colocada de uma forma nova pela vigência do paradigma biotecnocientífico e pelo decorrente essencialismo genético. $\mathrm{O}$ que é fundamentalmente humano, e o caracteriza, não é sua mente ou seu corpo. É o código genético - esse poderoso ícone cultural contemporâneo - que explica as características corporais e aptidões mentais. Nesse sentido, o essencialismo genético inaugura uma nova fase para a discussão sobre a condição humana, em que o ser humano em sua complexidade social, histórica e moral, seria predefinido por seus genes. O DNA, assim, torna-se o definitivo locus da identidade, o último e verdadeiro self 45 .

Atualmente, o DNA deriva seu apelo cultural da ciência e, por isso, adquire tamanha importância na representação coletiva do humano e de seu entorno. A nanotecnologia, como expoente do paradigma biotecnocientífico, não foge a esta narrativa de que o código genético determinaria o futuro humano. Todavia, ao apropriar-se desse simbolismo, a nanotecnologia acaba por ameaçá-lo, pois, no momento em que os cientistas elegem o DNA como material nanotecnológico ideal, eles nos propõem despi-lo de seu caráter simbólico de código da vida e ressignificá-lo. Dado o prestígio do discurso e da prática científica, esse fato certamente anuncia mudanças na representação daquilo que consideramos como "humano".

Por exemplo, o homem, já partido pela dicotomia de mente e corpo, é reduzido à expressão de seu conteúdo genético, o que se torna aparentemente legítimo com a vigência do paradigma biotecnocientífico. O DNA passa a ser um ícone cultural e científico tão poderoso, que todos os novos avanços biotecnológicos buscam utilizá-lo de alguma forma, para também gozar de seu prestígio social. A nanotecnologia não foge a este enfoque, uma vez que também faz do DNA seu material mais importante. Entretanto, essa promessa de transformar o ser humano, seu corpo, sua identidade individual e cultural gera o fascínio e o medo característicos dos avanços biotecnológicos, tornando o debate ético sobre a nanotecnologia tão acalorado. É neste ponto que a condição humana, como a conhecemos, é 
posta mais uma vez em questão: se o DNA passa a ser a base para a construção de tudo, torna-se banalizado e acaba por perder sua importância simbólica como a concebemos. Como isso atinge o humano?

O anúncio do uso massivo do DNA tem certamente importância ética determinada pelos possíveis impactos sobre a saúde do homem e de seu entorno. Estudos realizados demonstraram que nanoestruturas de RNA, quando introduzidas no conteúdo citoplasmático, podem apresentar efeitos negativos, como estresse celular, prejuízo das funções celulares e ruptura da membrana celular em virtude da característica de autorreplicação da molécula e seu rápido crescimento citoplasmático 52 .

\section{Conclusão}

A nanotecnologia como um todo e a transformação do DNA como matéria-prima ideal anunciam transformações significativas nos processos de produção, fazendo emergir discussões éticas a respeito de seus impactos na distribuição de benefícios e riscos relacionados à sua apropriação pelo mercado.

No entanto, talvez o que seja mais significativo do ponto de vista ético é a transformação cultural anunciada pela ressignificação do DNA. Despi-lo de seu caráter simbólico de código da vida, ou alterar de alguma forma essa representa- ção, pode trazer consequências expressivas para a própria representação atual do homem.

Por sua vez, o paradigma biotecnocientífico, devido à sua característica de intervenção e controle sobre os processos orgânicos, parece atingir seu auge com o uso do DNA como material nanotecnológico. As implicações éticas disso ilustram a capacidade que a nanotecnologia, em suas dimensões científicas, sociais e discursivas, tem de afetar o humano em sua saúde, o mundo em sua conjuntura sócio-econômica e toda a representação que o homem faz de si e de seu entorno.

Por fim, o caráter de incerteza que acompanha a busca de novas propriedades e a intervenção precisa sobre a programação molecular são aspectos novos da nanotecnologia em relação aos avanços anteriores. Contudo, talvez seja ainda mais significativa, do ponto de vista ético, a manipulação massiva da molécula de DNA. Certamente, serão colocadas questões referentes à toxicidade e ao meio-ambiente, mas as transformações culturais anunciadas podem ser ainda mais profundas. A alteração na condição humana não se dá somente porque a intervenção sobre o DNA será mais frequente e eficiente, mas também porque, ao anunciá-la como o mais promissor material nanotecnológico, a nanotecnologia acaba por ressignificá-lo. Assim fazendo, propõe uma ressignificação da condição humana, cujo futuro de fato é incerto, logo objeto das mais variadas especulações.

\section{Resumo}

A nanotecnologia é um conjunto formado por saberes, técnicas e práticas que estudam e exploram as novas propriedades dos materiais, quando manipulados em níveis atômicos e moleculares. A possibilidade técnica de organizar e controlar a matéria, desde suas menores dimensões e unidades, pode implicar profundas transformações no processo industrial de produção e ter consequências, moralmente significativas, sobre as inter-relações humanas, a organização da conjuntura social vigente e o próprio fenômeno da vida como um todo. No entanto, a reflexão moral a respeito da nanotecnologia tem sido alvo de críticas, como aquela de que a nanotecnologia não traria qualquer questão ética nova. O presente artigo pretende mostrar os limites desta afirmação e, para tanto, apresenta dois aspectos que diferenciam a nanotecnologia dos anteriores avanços biotecnocientíficos em suas possíveis implicações éticas: (a) a incerteza como característica epistêmica e (b) a ameaça ao presente caráter simbólico de código da vida do qual está imbuído o DNA.

Nanotecnologia; Bioética; Nanoestruturas; DNA 


\section{Colaboradores}

Os dois autores conceberam, estruturaram e revisaram o artigo.

\section{Agradecimentos}

Agradecemos ao Programa de Pós-graduação em Bioética da Universidade de Brasília pelo suporte para a formulação deste artigo.

\section{Referências}

1. Jones RAL. What has nanotechnology taught us about contemporary technoscience? In: Zülsdorf T, Coenen C, Ferrari A, Fiedeler U, Milburn C, Wienroth M, editors. Quantum engagements: social reflections of nanoscience and emerging technologies. Amsterdam: IOS Press; 2011. p. 13-26.

2. Buzea C, Blandino IIP, Robbie K. Nanomaterials and nanoparticles: sources and toxicity. Biointerphases 2007; 2:MR17-172.

3. Bhattacharyya D, Singh S, Satnalika N, Khandelwal A, Jeon SH. Nanotechnology, big things from a tiny world: a review. International Journal of u- and eService, Science and Technology 2009; 2:29-38.

4. Kostoff RN, Koytcheff RG, Lau CGY. Structure of the nanoscience and nanotechnology applications literature. J Technol Transf 2008; 33:472-84.

5. MacNaghten P, Guivant JS. Converging citizens? Nanotechnology and the political imaginary of public engagement in Brazil and the United Kingdom. Public Underst Sci 2011; 20:207-20.

6. Kuhlbusch TAJ, Asbach C, Fissan H, Göhler D, Stintz M. Nanoparticle exposure at nanotechnology workplaces: a review. Part Fibre Toxicol 2011; 8:1-18.

7. Hubbs AF, Mercer RR, Benkovic SA, Harkema J, Sriram K, Schwegler-Berry D, et al. Nanotoxicology - a pathologist's perspective. Toxicol Pathol 2011; 39:301-24.

8. Proffitt F. Yellow light for nanotech. Science 2004; 305:762.

9. Service RF. Nanotechnology grows up. Science 2004; 304:1732-4.
10. Raj B. Regulating nanomedicine - can the FDA handle it? Curr Drug Deliv 2011; 8:227-34.

11. Mauter MS, Elimelech M. Environmental applications of carbon-based nanomaterials. Environ Sci Technol 2008; 42:5843-59.

12. Klaine SJ, Alvarez PJJ, Batley GE, Fernandes TF, Handy RD, Lyon DY, et al. Nanomaterials in the environment: behavior, fate, bioavailability, and effects. Environ Toxicol Chem 2008; 27:1825-51.

13. Salvarezza RC. Why is nanotechnology important for developing countries? In: Proceedings of the Third Session of the World Commission on the Ethics of Scientific Knowledge and Technology. Rio de Janeiro: United Nations Educational, Scientific and Cultural Organization; 2003. p. 134-6.

14. Schramm FR. Paradigma biotecnocientífico e paradigma bioético. In: Oda LM, organizadora. Biosafety of transgenic organisms in human health products. Rio de Janeiro: Fundação Oswaldo Cruz 1996. p. 109-27.

15. Jotterand F. Nanotechnology, bioethics and the techno-scientific revolution: philosophical and ethical assessment of nanotechnology and its applications in medicine [Doctoral Dissertation]. Houston: Rice University; 2005.

16. Overly D. Lonely hearts of the cosmos: the scientific quest for the secret of the universe. New York: Harper Collins; 1991.

17. Schramm FR. Bioética, biossegurança e a questão da interface no controle das práticas da biotecnociência: uma introdução. Redbioética 2010; 1 : 99-110. 
18. Wickson F, Grieger K, Baun A. Nature and nanotechnology: science, ideology and policy. International Journal of Emerging Technologies and Society 2010; 8:5-23.

19. Olivé L. El bien, el mal y la razón: facetas de la ciencia y de la tecnología. México DF: Paidós; 2000.

20. Schramm FR. Existem boas razões para se temer a biotecnociência? Bioethikos 2010; 4:189-97.

21. Fischer M. Futuros antropológicos: redefinindo a cultura na era tecnológica. Rio de Janeiro: Jorge Zahar Editor; 2011.

22. Khushf G. The ethics of NBIC convergence. J Med Philos 2007; 32:185-96.

23. Litton P. 'Nanoethics'? What's new? Hastings Cent Rep 2007; 37:22-5.

24. Nordmann A. If and then: a critique of speculative nanoethics. Nanoethics 2007; 1:31-46.

25. Allhoff F. On the autonomy and justification of nanoethics. Nanoethics 2007; 1:185-210.

26. Nordmann A. Molecular disjunctions: staking claims at the nanoscale. In: Baird D, Nordmann A, Schummer J, editors. Discovering the nanoscale. Amsterdam: IOS Press; 2004. p. 51-62.

27. Stirling A. Risk, precaution and science: towards a more constructive policy. EMBO Rep 2007; 8: 309-15.

28. Ferrari A. Developments in the debate on nanoethics: traditional approaches and the need for new kinds of analysis. Nanoethics 2010; 4:27-52.

29. Clift R. Nanotechnology: an example of risk management and regulation in an emerging technology. In: Proceedings of Special Session of the Joint Meeting: Potential Implications of Manufactured Nanomaterials for Human Health and Environmental Safety; 2005. http://sei.nnin.org/doc/ resource/clift\%20report.pdf (acessado em 10/ Fev/2012).

30. Weckert J, Moor J. The precautionary principle in nanotechnology. Int J Appl Philos 2006; 20: 191-204.

31. Grunwald A. Nanotechnology: a new field of ethical inquiry? Sci Eng Ethics 2005; 11:187-201.

32. Harris J, Holm S. Extending human lifespan and the precautionary paradox. J Med Philos 2002; 27:355-68.

33. Holm S. Reply to Sandin: the paradox of precaution is not dispelled by attention to context. Camb Q Healthc Ethics 2006; 15:184-7.

34. Peterson $\mathrm{M}$. The precautionary principle is incoherent. Risk Anal 2006; 26:595-601.

35. Sandler R. Nanotechnology: the social and ethical issues. Washington DC: Woodrow Wilson International Center for Scholars, Project on Emerging Technologies; 2009. http://www.nanotechproject. org/process/assets/files/7060/nano_pen16_final. pdf (acessado em 10/Fev/2012)
36. Sparrow R. Revolutionary and familiar, inevitable and precarious: rhetorical contradictions in enthusiasm for nanotechnology. Nanoethics 2007; 1:57-68.

37. Pyrrho M. Nanotechnology and ethics: assessing the unforeseeable. In: Rudnick A, editor. Bioethics in the 21st century. Rijeka: Intech; 2011. p. 121-38.

38. National Science and Technology Council. National Nanotechnology Initiative: leading to the next industrial revolution: a report by the Interagency Working Group on Nanoscience, Engineering and Technology Committee on Technology; 2000. http://clinton4.nara.gov/WH/ New/html/20000121_4.html (acessado em 09/ Fev/2012).

39. Drexler KE. Nanotechnology: from Feynman to funding. Bull Sci Technol Soc 2004; 24:21-7.

40. Bostrom N. Technological revolutions: ethics and policy in the dark. In: Cameron NMS, Mitchell ME, editors. Nanoscale: issues and perspectives for the nanocentury. New Jersey: Wiley; 2007. p. 129-52.

41. Roco MC. Nanotechnology: from discovery to innovation and socioeconomic projects. Chem Eng Process 2011; 171:21-7.

42. Roco MC. International strategy for nanotechnology. J Nanopart Res 2001; 3:353-60.

43. Wonglimpiyarat J. Nanotechnology: a successive industrial revolution of Schumpeter's long wave theory. International Journal of Nanotechnology 2004; 1:480-90.

44. Franklin S. Science as culture, cultures of science. Annu Rev Anthropol 1995; 24:163-84.

45. Nelkin D, Lindee MS. The DNA mystique: the gene as a cultural icon. New York: Freeman; 1995.

46. Zebrowski, Robin L. Altering the body: nanotechnology and human nature. Int J Appl Philos 2006; 20:229-46.

47. Lin P, Allhoff F. Nanoethics and human enhancement: a critical evaluation of recent arguments. Nanotech Perceptions 2006; 2:47-52.

48. Liu Y, Yan H. Designer curvature. Science 2009; 325:685-6.

49. Aldaye FA, Palmer AL, Sleiman HF. Assembling materials with DNA as the guide. Science 2008 321:1795-9.

50. Koyrè A. As origens da ciência moderna: uma nova interpretação. In: Koyrè A, organizador. Estudos de história do pensamento científico. 2a Ed. Rio de Janeiro: Forense Universitária; 1991. p. 56-79.

51. Schramm FR. Bioética e moralidade das biotecnologias. In: Emerick MC, Valle S, Costa MAF, coordendores. Gestão biotecnológica: alguns tópicos. Rio de Janeiro: Interciência; 1999. p. 123-30.

52. Thodey K, Smolke CD. Bringing it together with RNA. Science 2011; 333:412-3.

Recebido em 28/Fev/2012 Aprovado em 17/Ago/2012 
